\title{
EDITORIAL
}

DOI: $10.53116 /$ pgaflr.2021.1.1

\section{Progress and Tradition}

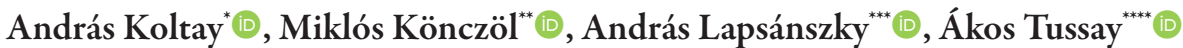

* University of Public Service, e-mail: koltay.andras@uni-nke.hu

**Centre for Social Sciences, e-mail: konczol.miklos@tk.hu

***University of Győr, e-mail: lapsanszky.andras@sze.hu

**** University of Public Service, e-mail: tussay.akos@uni-nke.hu

The journal, Public Governance, Administration and Finances Law Review (PGAF LR) was launched in 2016 as a Central and Eastern European based law journal which was committed to facilitating an interdisciplinary forum of public law within the so-called Visegrád countries. Over the past six years, the journal's Editorial Team was constantly facing with a somewhat thorny issue, namely a theoretical discussion of CEE problems might, in many cases, not be confined within the journal's original and initial aims and scope. As a result of this, the Editorial Team was forced to refuse otherwise relevant pieces of scholarship, or to accept papers that strictly-speaking did not fall within the journal's scope.

In 2020, after publishing five volumes with a total number of ten issues, the Editorial Board decided to put an end to the above-mentioned practice and transform PGAF LR into a law journal with global coverage that accepts articles on all facets of public administration, public policy and public management within the region and with other parts of the world as well. As part of this transformation, the Editorial Board was partly renewed and several new members outside of the CEE area were invited to join. This process also brought along some changes within the Editorial Team itself. The work, which was initiated by PGAF LR's two past editors, Gábor Hulkó and Tamás Kaiser, is now shared, under the watchful eye of founder Editor-in-Chief, András Lapsánszky, among three new editors: András Koltay, who is also the Rector of the University of Public Service, Miklós Könczöl, who is currently editor of two other prestigious Hungarian journals and Ákos Tussay, former secretary of the previous Editorial Team.

However, this transformation signals neither the end of a progress, nor a break with past traditions; rather, the Editorial Team wishes to uphold all the values, academic commitments and good practices that characterised the journal's past six years of operation. As a manifest sign of this expectation, the Editorial Team has decided to even continue with the former editors' last initiative, namely, as a follow up to the Pandemic 
and Governance conference, organised in November 2020, the editors convened a second conference, Post-Pandemic Politics: Perspectives and Possibilities, in June 2021. Encouraged by the conference's success, the Editorial Team invited the conference's speakers to submit their manuscripts to be published in the journal's pending issue.

Thus, the first issue of our 2021 volume is partly a conference proceeding and partly an ordinary issue. The list of its articles is opened by the conference's keynote speaker's, Raphael Cohen-Almagor's, paper who considers Israel's response to the challenges raised by the Covid-19 pandemic with a specific focus on the invoked public policies and the related political, economic and legal concerns. After outlining the keys for the initial Israeli success, namely, the government's swift and effective reaction to the pandemic, the close cooperation and coordination between the organisations that were mobilised to counter the pandemic, and the effective implementation of governmental policies, the Author indulges into a fuller consideration of the mistakes and the moral of the vaccination campaign too.

The second paper is Bence Gát's Coronavirus Test of the European Union's Policy on the Rule of Law. In this article, the Author gives a general overview of the European Union's approach towards the idea of the rule of law just to set out that an extraordinary situation, such as the current pandemic, reveals that the EU institutions cannot provide sufficient guarantees for any objective examination of the issue.

Next, István Hoffman and István Balázs's article describes the impact of Covid-19 on the Hungarian body of administrative law. They argue that several new rules have been incorporated into the Hungarian legal system and that the legislative background' of the pandemic offered an opportunity to the central government to pass significant, yet rather controversial reforms.

The fourth study is Mina Hosseini's article which raises legal and ethical concerns regarding those dilemmas that hinge around the production and distribution of Covid-19 vaccines. As a possible solution the Author proposes the need to emphasise the vital significance of public rights as opposed to focusing exclusively on individual rights, such as those intellectual property rights that hinder the world-wide manufacturing of Covid-19 vaccines.

In the fifth article, András Karácsony and Szabolcs Nagypál investigate how and by what constitutional mandate the Hungarian Government deviated from the normal constitutional situation in 2020. Based on Carl Schmitt's and Giorgio Agamben's idea of the 'state of exception', they argue that the Hungarian situation in 2020 did not fall within this category; rather, it shall be described as an extraordinary situation.

Finally, the last article of the conference's proceedings is a study from Oana Şerban in which the Author proposes that the models of good governance in the post-pandemic world must be shaped by leftist principles, in order to ensure not the reopening, but the reconstruction of public life.

Next to these six conference papers, the present issue publishes two research articles as well. The first article is authored by Tibor Buskó and it provides an all-encompassing overview of the lower-middle level of public administration in Hungary, while Csaba Lentner's study endeavours to outline the development of Hungary's monetary policy from the late 1980s to the present. 